\title{
Immunohistochemical characterisation of cells co-producing insulin and glucagon in the developing human pancreas
}

\author{
M. J. Riedel • A. Asadi • R. Wang • Z. Ao • \\ G. L. Warnock • T. J. Kieffer
}

Received: 28 June 2011 / Accepted: 30 August 2011 / Published online: 25 October 2011

(C) Springer-Verlag 2011

\begin{abstract}
Aims/hypothesis In adult human islets, insulin and glucagon production is largely restricted to individual cell populations. The production of these hormones is less segregated during development and during the differentiation of human pluripotent stem cells towards pancreatic lineages. We therefore sought to characterise the transcription factor profile of these cells that co-produce insulin and glucagon in the developing human pancreas, and thus to gain insight into their potential fate during normal pancreas development.

Methods An immunohistochemical analysis was performed on human pancreas sections from fetal donors aged 9 to 21 weeks and from adult donors between the ages of 17 and 55 years.

Results Endocrine cells were observed within the pancreas at all ages examined, with cells co-producing insulin and glucagon observed as early as 9 weeks of fetal age. The
\end{abstract}

M.J. Riedel and A. Asadi contributed equally to this study.

Electronic supplementary material The online version of this article (doi:10.1007/s00125-011-2344-9) contains peer-reviewed but unedited supplementary material, which is available to authorised users.

M. J. Riedel • A. Asadi · T. J. Kieffer $(\bowtie)$

Laboratory of Molecular and Cellular Medicine, Department of

Cellular and Physiological Sciences, Life Sciences Institute, 2350

Health Sciences Mall, University of British Columbia,

Vancouver, BC, Canada V6T 1Z3

e-mail: tim.kieffer@ubc.ca

R. Wang

Children's Health Research Institute, Victoria Research

Laboratory Centre, University of Western Ontario,

London, ON, Canada

Z. Ao $\cdot$ G. L. Warnock $\cdot$ T. J. Kieffer

Department of Surgery, University of British Columbia,

Vancouver, BC, Canada population of cells that co-produce insulin and glucagon generally decreased in prevalence with age, with negligible numbers in adult pancreas. From 9 to 16 weeks, the population of glucagon-only cells increased, while the insulin-only cells decreased in abundance. Cells that coproduced insulin and glucagon also produced the alpha cell transcription factor, aristaless related homeobox (ARX), and lacked the beta cell transcription factors pancreatic and duodenal homeobox 1 (PDX1), NK6 homeobox 1 (NKX6.1) and v-maf musculoaponeurotic fibrosarcoma oncogene homologue A (MAFA).

Conclusions/interpretation Our results indicate that cells co-producing insulin and glucagon in the developing human pancreas share a transcription factor profile that is similar to that of mature alpha cells and suggest that some maturing alpha cells briefly exhibit ectopic insulin expression. Thus cells that co-produce insulin and glucagon may represent a transient cell population, which gives rise to mature alpha cells.

Keywords Development · Fetal · Glucagon · Human · Immunofluorescence $\cdot$ Insulin $\cdot$ Islet $\cdot$ Pancreas ·

Transcription factor

$\begin{array}{ll}\text { Abbreviations } \\ \text { ARX } & \text { Aristaless related homeobox } \\ \text { E } & \text { Embryonic day } \\ \text { MAF } & \text { v-Maf musculoaponeurotic fibrosarcoma } \\ & \text { oncogene homologue } \\ \text { NKX2.2 } & \text { NK2 homeobox 2 } \\ \text { NKX6.1 } & \text { NK6 homeobox 1 } \\ \text { PAX } & \text { Paired box } \\ \text { PCNA } & \text { Proliferating cell nuclear antigen } \\ \text { PDX1 } & \text { Pancreatic and duodenal homeobox 1 } \\ \text { PP } & \text { Pancreatic polypeptide }\end{array}$

Abbreviations

ARX Aristaless related homeobox

E Embryonic day

MAF v-Maf musculoaponeurotic fibrosarcoma

NKX2.2 NK2 homeobox 2

NKX6.1 NK6 homeobox 1

PAX Paired box

PDX1 Pancreatic and duodenal homeobox 1

Pancreatic polypeptide 


\section{Introduction}

The successful implementation of a human pluripotent stem cell-based therapy for the treatment of type 1 diabetes will require a differentiation protocol that promotes the efficient and stable production of mature insulin-producing beta cells. Understanding the developmental pathways that regulate the formation of the pancreas has significantly advanced stem cell differentiation protocols, but the exact mechanisms leading to mature beta cell formation in humans are not yet known. Much of our current understanding of the pathways involved in pancreatic organogenesis comes from genetic studies in mice; however, immunohistochemical studies of human fetal pancreases have yielded some insightful results. The human pancreas forms as separate dorsal and ventral protrusions that arise from the foregut endoderm, around 26 days postconception [1]. Insulin-positive cells appear first near 7 weeks of fetal age, followed 1 week later by cells producing glucagon, somatostatin or pancreatic polypeptide (PP) [1]. During the development of these endocrine cells, a specific temporal pattern of transcription factor production is required to achieve the appropriate cell fate. In early stages, the developing endocrine cells share production of key transcription factors, including neurogenin 3 (NGN3) and paired box (PAX)6. These factors are thought to delineate the endocrine precursor cell population from which all islet endocrine cells are formed. As these immature endocrine cells develop, each cell type adopts a unique transcription factor profile. For example, mature alpha cells produce aristaless related homeobox (ARX), but not PAX4 or pancreatic and duodenal homeobox 1 (PDX1) $[2,3]$. Conversely, beta cells produce PDX1, NK6 homeobox 1 (NKX6.1) and v-maf musculoaponeurotic fibrosarcoma oncogene homologue (MAF)A, but not ARX [3]. Several studies have reported the existence of a transient population of developing endocrine cells that coproduce insulin and glucagon $[4,5]$. Electron microscopic analysis of mid-gestational human fetal pancreas revealed the presence of insulin and glucagon protein within the same secretory granules in immature endocrine cells [4]. In addition, double in situ hybridisation experiments in the human fetal pancreas have demonstrated the co-expression of insulin and glucagon mRNA within the same cells [5].

The ultimate fate of cells co-producing insulin and glucagon in the adult mouse and human islet is not known. Using Cre-mediated lineage tracing techniques, Herrera suggested that insulin or glucagon promoter activity was not previously active in mature alpha or beta cells, respectively [6]. In contrast, previous studies had suggested that the population of cells co-producing insulin and glucagon may be precursors to mature endocrine cell types $[7,8]$. Expression of diphtheria toxin A chain driven by the insulin promoter resulted in a slight decrease in mature alpha cell number in the developing pancreas, suggesting that insulin promoter activity was active in at least a subset of glucagon-producing cells [7]. Furthermore, Alpert and colleagues demonstrated that the insulin promoter was active at low levels in all glucagon-positive cells in the early mouse pancreas [8]. In the current study, we performed a comprehensive immunohistochemical analysis of the developing human pancreas. We focused on the transcription factor profile of cells co-producing insulin and glucagon, in order to clarify their potential role in the development of mature islets.

\section{Methods}

Human tissues Human fetal pancreases were collected according to protocols approved by the Health Sciences Research Ethics Board at the University of Western Ontario. Human adult pancreases were provided by the Irving $\mathrm{K}$. Barber Human Islet Isolation Laboratory (Vancouver, BC, Canada) with consent to use for research purposes.

Immunofluorescence Human fetal (9-21 weeks) and human adult pancreas tissues were fixed in $4 \%$ (wt/vol.) paraformaldehyde, embedded in paraffin and sectioned (Wax-it Histology Services, Vancouver, BC, Canada). Immunofluorescence staining was performed as previously described [9]. Non-commercial antibodies towards PDX1 were graciously provided by J. Habener (Massachusetts General Hospital, Boston, MA, USA) and C. Wright (Vanderbilt University, Nashville, TN, USA). The antibody towards ARX was a kind gift from P. Colombat (Inserm, University of Nice, Nice, France). The NK2 homeobox 2 (NKX2.2) antibody developed by T. Jessel (Department of Biochemistry and Molecular Biophysics, Columbia University, New York, NY, USA) was obtained from Developmental Studies Hybridoma Bank developed under the auspices of the National Institute of Child Health and Human Development (NICHD) and maintained by The University of Iowa, Department of Biological Sciences, Iowa City, IA, USA. Antibodies towards NKX6.1 and MAFA were kindly provided by A. Rezania (BetaLogics Venture, Skillman, NJ, USA). Primary antibodies are listed in Electronic supplementary material (ESM) Table 1. Primary antibody staining was visualised by secondary staining with Alexafluor 350, 488, 555, 594 or 647 dyes (Invitrogen, Carlsbad, CA, USA).

Image acquisition and analysis Images were collected using either (1) a microscope (Axiovert 200; Carl Zeiss, Toronto, ON, Canada) connected to a digital camera (Retiga 2000R; QImaging, Surrey, BC, Canada) controlled with Openlab 5.2 software (Perkin Elmer, Waltham, MA, 
USA) or (2) an automated imaging system (ImageXpress Micro Imaging System). Images were analysed using MetaXpress (Molecular Devices, Sunnyvale, CA, USA).

Quantification analysis To quantify the number of cells producing glucagon or insulin, or both proteins, pancreas sections ( $n=3-6$ for each group) were co-immunostained with antibodies directed against insulin and glucagon. Nuclei were labelled with DAPI. Automated image acquisition captured the entire pancreas section using emission filters for FITC (536/40), Texas Red (624/40) and DAPI (447/60). Separate filter cubes were used for each acquisition to minimise effects of spectral overlap. Individual images were combined using MetaXpress to recreate the entire pancreas section. The Multi Wavelength Cell Scoring module in MetaXpress was used to identify all nuclei and assess for production of glucagon or insulin, or both hormones (ESM Fig. 1). Data are expressed as the percentage of hormoneproducing cells (defined here as cells producing insulin or glucagon, or both hormones) among total pancreatic cells as defined by DAPI nuclear staining, or as the percentage of cells producing or co-producing insulin and/or glucagon relative to the total of hormone-producing cells in each pancreas section.

Statistical analysis Quantification data are expressed as mean \pm SE. Asterisks in bar graphs indicate significance at $p<0.05$ by unpaired Student's $t$ test.

\section{Results}

Quantification of cells co-producing insulin and glucagon during human pancreas development To characterise the production of insulin and glucagon during human pancreas development, we performed a detailed quantitative analysis of insulin and glucagon immunoreactivity in the fetal pancreas between 9 and 21 weeks, and in the adult pancreas (Figs 1 and 2; ESM Figs 1 and 2, ESM Table 2). During this critical window of development, the pattern of insulin and glucagon staining in the pancreas evolves from a smattering of insulin-producing cells to cohesive islet structures similar to those found in the adult organ. Despite a gross morphological change, the proportion of cells producing insulin and/or glucagon remained relatively constant throughout this period of development. At 9 to 10 weeks, these endocrine cells accounted for $1.31 \pm 0.31 \%$ of the total pancreatic cell population; at 21 weeks, this population was $2.69 \pm 0.88 \%$ (Fig. 2a). In the adult pancreas, $1.38 \pm 0.31 \%$ of cells within the pancreas were immunoreactive for insulin and/or glucagon (Fig. 2a).

To further examine the composition of the insulin- and glucagon-producing cell populations, we expressed their
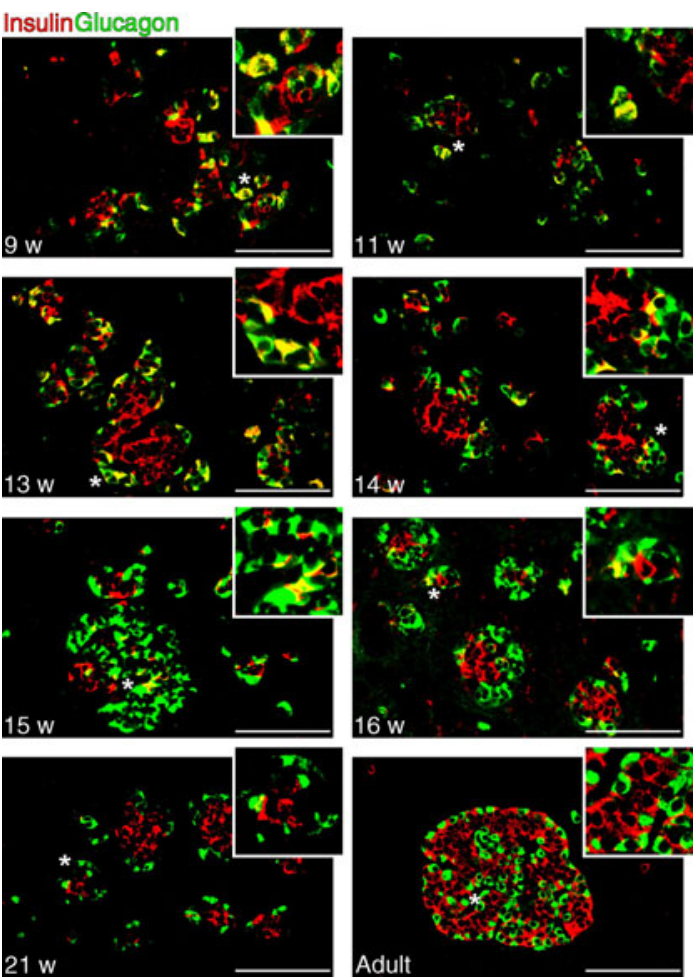

Fig. 1 Insulin- and/or glucagon-producing cells during human pancreas development. Double immunofluorescence staining for insulin (red) and glucagon (green) in human fetal (age in weeks [w] as indicated) and adult pancreas sections. Representative merged images are shown for each age; co-localisation of insulin and glucagon is in yellow. White asterisks $\left(^{*}\right)$ denote regions enlarged $(\times 4)$ in the upper-right corner. Scale bars, $100 \mu \mathrm{m}$

frequency relative to the total population of cells producing insulin and/or glucagon (Fig. 2b). Cells producing both insulin and glucagon were observed at all fetal ages examined, as well as in the adult pancreas. While this cell population comprised only $1.34 \pm 0.6 \%$ of all insulin- and/or glucagon-producing cells in the adult organ, it was much larger during fetal development. At 11 to 13 weeks of fetal development, this population was at its largest, comprising $28.79 \pm 5.60 \%$ of all cells producing insulin and/or glucagon. While the changes in the relative size of each quantified cell population were small between adjacent age ranges, a significant decrease in insulin-producing cells between 9 and 10 weeks, and 14 and 16 weeks was accompanied by a significant increase in the glucagonproducing cell population (Fig. 2b). At 21 weeks, the composition of these distinct cell populations resembled that of the adult pancreas (Fig. 2b).

Additional islet hormones are observed in some cells co-producing insulin and glucagon Given that early endocrine cells are capable of producing more than a single hormone, we investigated the possibility that cells coproducing insulin and glucagon also produce other islet 
a

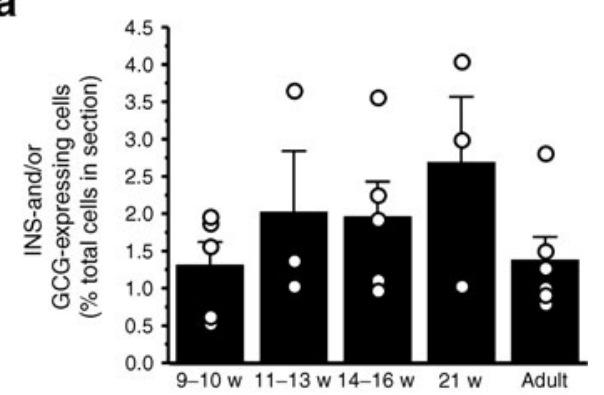

b

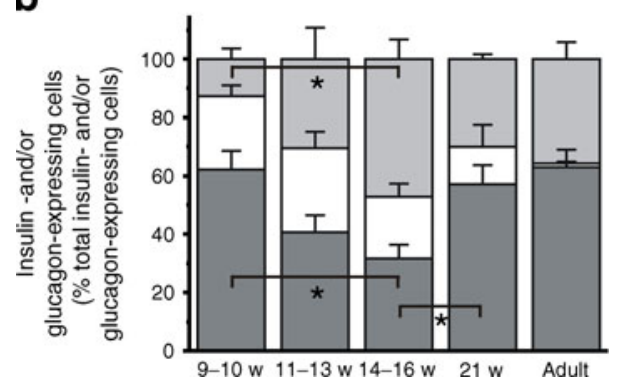

Fig. 2 Quantification of insulin and glucagon immunoreactivity in developing and adult human pancreas. a Quantification of pancreatic cells that produce insulin and/or glucagon as a percentage of the total number of cells in each examined pancreas section. White circles, individual data points for each analysed section. b Percentage of insulin-only (dark grey), glucagon-only (light grey) or double-positive (white) cells, relative to the total population of cells producing insulin and/or glucagon. Data are mean $\pm \mathrm{SEM} ; n=3-6$ sections per group; $* p<0.05$ between indicated groups

hormones. Somatostatin and PP were detected in cells coproducing insulin and glucagon. At 9 weeks, the frequency of these triple-positive cells was $<1$ in 1,000 (Fig. 3, ESM Fig. 3, ESM Fig. 4). By 15 weeks, somatostatin and PP production was restricted to separate cell populations, thus resembling the pattern in adult islets. In contrast, ghrelin immunoreactivity did not co-localise with insulin and/or glucagon immunoreactivity at any of the examined developmental time points (Fig. 3, ESM Fig. 5), suggesting a separate cell ancestry for this rare islet cell type.

Consistent with observations made over 30 years ago [10], we observed two distinct islet architectures with respect to PP production in the developing human pancreas (ESM Fig. 6). Thus while PP production was limited to a few cells in the majority of islets, some fetal islets were comprised almost entirely of PP-producing cells that did not co-produce insulin or glucagon (ESM Fig. 6).

Transcription factor profiling of cells co-producing insulin and glucagon To further characterise the molecular identity of the cells co-producing insulin and glucagon, we analysed the abundance of key transcription factors in this cell population during human pancreas development. In the developing mouse pancreas, PAX6 production is observed throughout the pancreatic epithelium as early as embryonic
day(E) 9 , prior to the production of insulin or glucagon. By E9.5, some PAX6-positive cells begin to produce glucagon, while insulin-positive cells arise from the PAX6-producing population at E12.5. Whereas PAX6 production is not absolutely required for endocrine cell development, absence of this protein in the developing mouse pancreas results in a significant reduction of endocrine cell numbers $[11,12]$ and hormone levels [13]. In the 9-week-old developing fetal human pancreas, we observed PAX6 production in all insulin- and/or glucagon-producing cells (Fig. 4). This pattern appears to be maintained throughout fetal development and into the adult pancreas, where PAX6 is produced in mature alpha and beta cells (Fig. 4).

MAFA and MAFB are basic leucine zipper transcription factor family members produced in the developing pancreas. Production of MAFA in the developing mouse pancreas is first observed at E13.5 in the NKX6. $1^{+} /$insulin $^{+}$cell population [14]. While MAFA production is not required for beta cell formation, it regulates insulin gene transcription and may play a role in the maintenance of normal function in the mature beta cell $[15,16]$. MAFB production in the developing mouse pancreas is observed earlier than MAFA in immature alpha and beta cells [17]. In the adult mouse, MAFB is restricted to mature alpha cells and is absent from mature beta cells [18]. In the human pancreas, the production patterns of MAFA and MAFB are less well characterised. Sarkar and colleagues reported that MAFA mRNA levels remained low throughout pancreas development, but were significantly upregulated in adult islets [19]. We observed MAFA production throughout the developing pancreatic epithelium at 9 weeks (Fig. 4). Two distinct levels of production were detectable, with strong nuclear immunoreactivity observed in cells producing insulin, and weaker immunoreactivity observed in the remaining pancreatic epithelium. Cells that produced both insulin and glucagon exhibited either weak or no nuclear MAFA immunoreactivity. In some cells co-producing insulin and glucagon, MAFA immunoreactivity was detected in the cytoplasm, but not in the nucleus (data not shown), suggesting that the protein may be inactive in these cells. Interestingly, we observed changes in location and intensity of MAFA immunoreactivity as the pancreas developed. At 13 weeks, nuclear MAFA immunoreactivity was faint in most cells producing insulin only and absent from all cells producing glucagon with or without insulin. Weak cytoplasmic MAFA immunoreactivity was observed in some cells producing one or both hormones. At 15 weeks, nuclear MAFA immunoreactivity was only rarely observed, while most insulin- and/or glucagon-producing cells exhibited weak cytoplasmic MAFA production (Fig. 4). At 21 weeks, MAFA immunoreactivity was not observed. In agreement with observations in the mouse, beta cellspecific nuclear localised MAFA immunoreactivity was 
Fig. 3 Other islet hormones in cells producing insulin and/or glucagon during human pancreas development. Triple immunofluorescence staining for insulin (red), glucagon (blue), and somatostatin (SST) (green), PP (green) or ghrelin (GHR) (green) in human fetal (age in weeks $[\mathrm{w}]$ as indicated) and adult pancreas sections. White asterisks $(*)$ denote regions enlarged $(\times 4)$ in the upper-right corner of each image. Scale bars, $100 \mu \mathrm{m}$
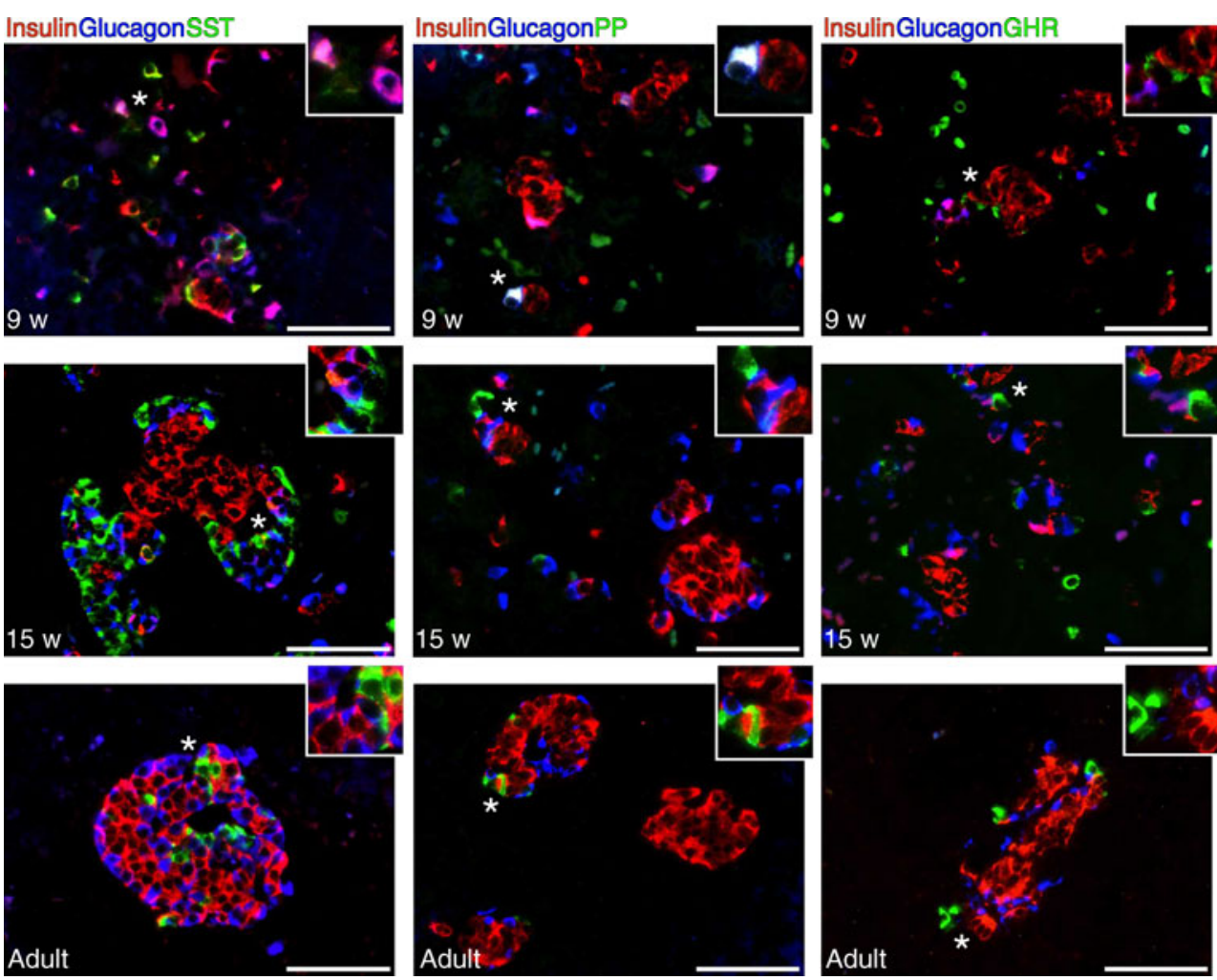

observed in adult human islets (Fig. 4). In contrast, MAFB production in the adult human pancreas differs from that observed in the mouse, with immunoreactivity observed in
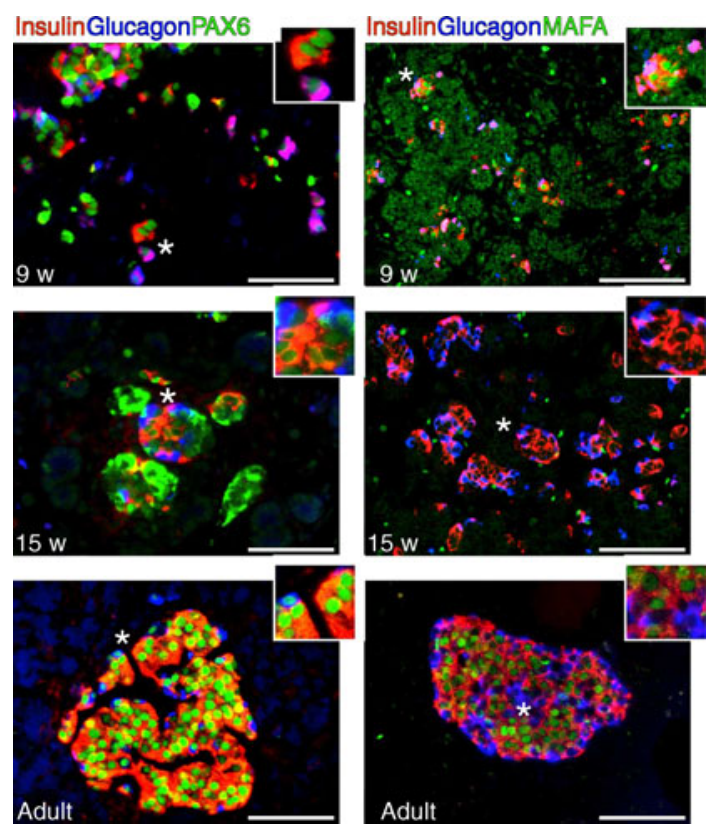

Fig. 4 Transcription factors PAX6 and MAFA in cells producing insulin and/or glucagon during human pancreas development. Triple immunofluorescence staining for insulin (red), glucagon (blue), and PAX6 (green) or MAFA (green) in human fetal (age in weeks [w] as indicated) and adult pancreas sections. White asterisks $\left({ }^{*}\right)$ denote regions enlarged $(\times 4)$ in the upper-right corner of each image. Scale bars, $100 \mu \mathrm{m}$ mature alpha and beta cells (Fig. 5). This is in agreement with a recent report indicating that adult human beta cells are enriched in $M A F B$ mRNA [20]. MAFB immunoreactivity was also observed in cells co-producing insulin and glucagon at all developmental ages examined (Fig. 5).

In the developing mouse pancreas, the NK homeodomain protein NKX2.2 is first produced in the developing pancreatic epithelium at E9.5, subsequently becoming restricted to the NGN3-positive endocrine progenitor pool [21]. In the adult mouse pancreas, NKX2.2 is produced in alpha and beta cells [22]. Lyttle and colleagues have previously shown that at 10,14 and 21 weeks, NKX2.2 production can be observed in insulin-positive and glucagon-positive cells [23]. In agreement with these results, we observed NKX2.2 production in all cells producing insulin and/or glucagon, regardless of the age examined (Fig. 6, ESM Fig. 7)

NKX6.1 also plays a significant role in the developing endocrine pancreas. In the mouse, NKX6.1 is widespread in the early developing pancreatic epithelium. A lack of NKX6.1-positive cells in the $P d x 1$-null mouse [24] suggests that production of NKX6.1 is activated downstream of PDX1 in the developing pancreas. NKX6.1 production becomes increasingly restricted to the beta cell compartment in the wild-type mouse and is maintained in adult islets [25]. In human pancreases, we observed a similar pattern of ubiquitous epithelial production of NKX6.1 at 9 weeks, at a time when PDX1 production is also widespread (Fig. 7). At 13 weeks, production of NKX6.1 

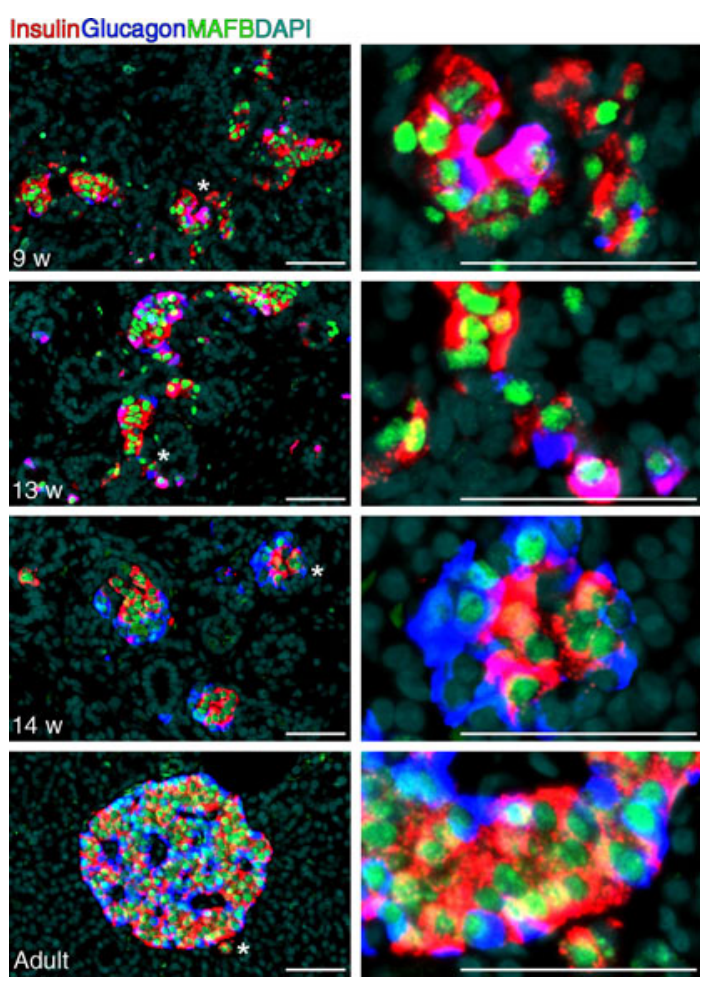

Fig. 5 Transcription factor MAFB in cells producing insulin and/or glucagon during human pancreas development. Triple immunofluorescence staining for insulin (red), glucagon (blue) and MAFB (green) in human fetal (age in weeks [w] as indicated) and adult pancreas sections. White asterisks $\left(^{*}\right)$ denote regions enlarged in the right column. Nuclei stained with DAPI are shown in cyan. Scale bars, $50 \mu \mathrm{m}$

remained high in cells producing insulin only, and was weaker in other cell types (Fig. 6, ESM Fig. 8). In the adult pancreas, NKX6.1 production was limited to cells producing insulin only (Fig. 6, ESM Fig. 8). Interestingly, cells that coproduced insulin and glucagon lacked NKX6.1 immunoreactivity throughout development.

Although PDX1 plays a critical role in the initial budding of the pancreas from the foregut in early development, it also plays a role in maintaining the survival and mature phenotype in beta cells $[26,27]$. Conversely, ARX is required to maintain the mature alpha cell phenotype, possibly by opposing the beta cell-differentiating properties of PAX4 $[2,28]$. As observed in adult mouse islets, PDX1 and ARX exhibit opposite production profiles in adult human islets, with PDX1 production largely limited to beta cells and ARX production limited to alpha cells (Fig. 8, ESM Fig. 9). At 9 weeks, PDX1 production was observed throughout the developing pancreatic epithelium (Fig. 7). As expected, all cells positive for insulin only produced PDX1, but cells coproducing insulin and glucagon were PDX1-negative (Fig. 8, ESM Fig. 9). Lack of PDX1 production in cells positive for both insulin and glucagon was observed throughout the developing pancreas (Fig. 8, ESM Fig. 9). By 14 weeks,
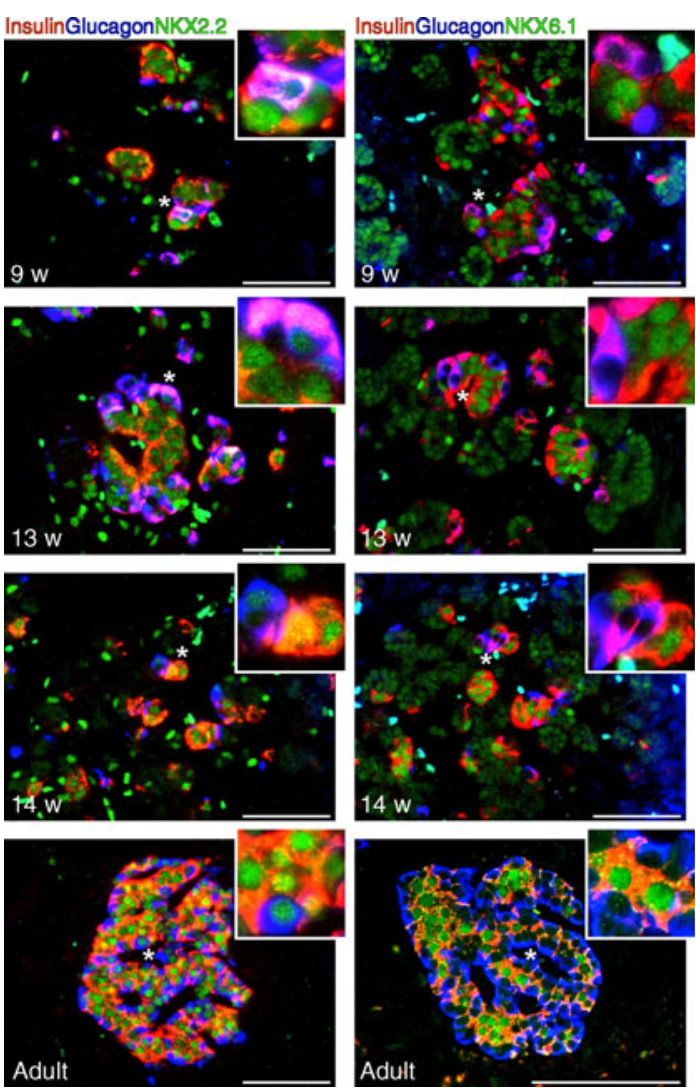

Fig. 6 Transcription factors NKX2.2 and NKX6.1 in cells producing insulin and/or glucagon during human pancreas development. Triple immunofluorescence staining for insulin (red), glucagon (blue), and NKX2.2 (green) or NKX6.1 (green) in human fetal (age in weeks [w] as indicated) and adult pancreas sections. White asterisks $\left(^{*}\right)$ denote regions enlarged $(\times 4)$ in the upper-right corner of each image. Scale bars, $100 \mu \mathrm{m}$

levels of PDX1 were decreased in insulin-negative cells, while robust production was maintained in the maturing beta

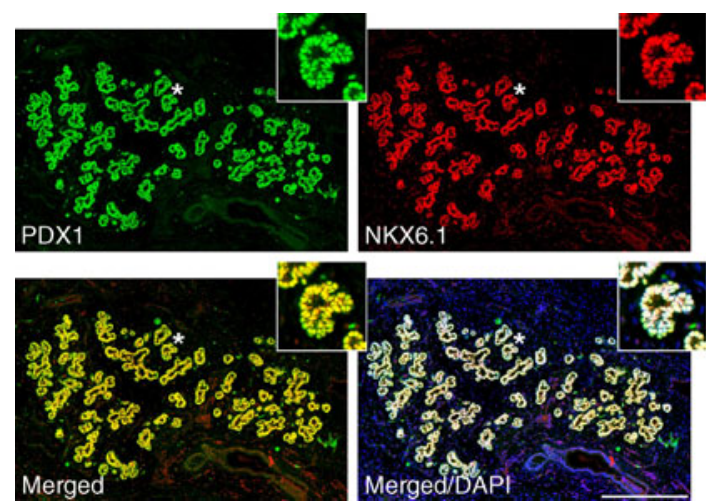

Fig. 7 Widespread co-production of transcription factors PDX1 and NKX6.1 in pancreatic epithelial cells at 9 weeks of human fetal pancreas development. Double immunofluorescence staining for PDX1 (green) and NKX6.1 (red) in human fetal pancreas sections at 9 weeks, with merged images (DAPI, blue). Triple-labelled nuclei appear white. White asterisks $(*)$ denote regions enlarged $(\times 4)$ in the upper-right corner of each image. Scale bar $300 \mu \mathrm{m}$ 

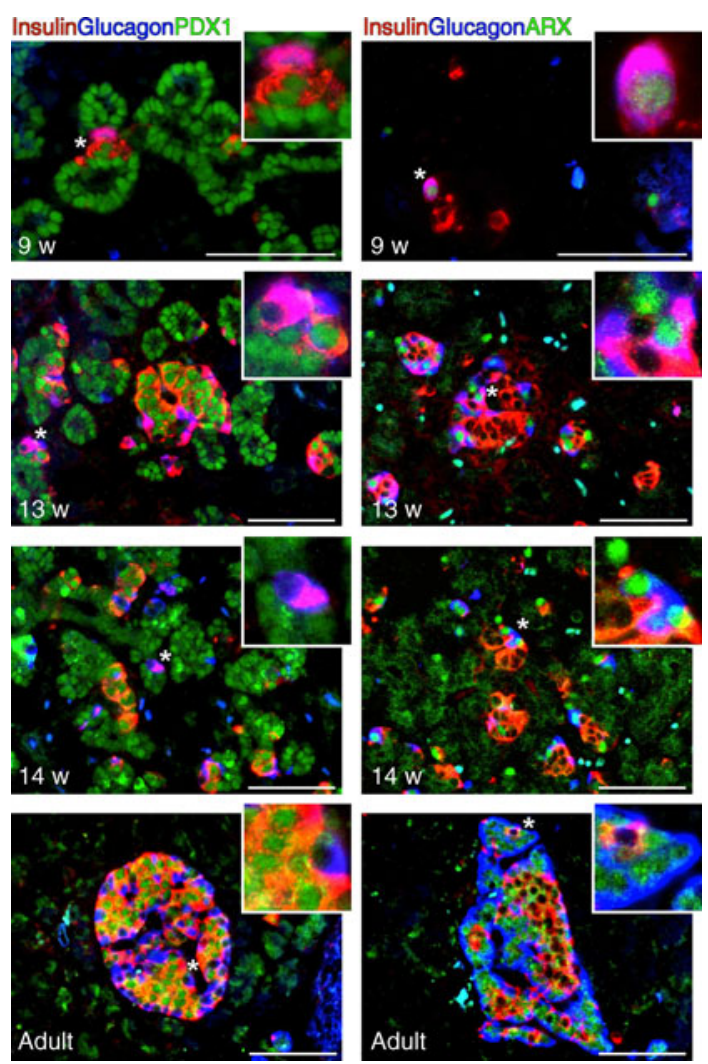

Fig. 8 Transcription factors PDX1 and ARX in cells producing insulin and/or glucagon during human pancreas development. Triple immunofluorescence staining for insulin (red), glucagon (blue), and PDX1 (green) or ARX (green) in human fetal (age in weeks [w] as indicated) and adult pancreas sections. White asterisks $\left({ }^{*}\right)$ denote regions enlarged $(\times 4)$ in the upper-right corner of each image. Scale bars, $100 \mu \mathrm{m}$

cells (Fig. 8, ESM Fig. 9). While PDX1 remained detectable in the nuclei of adult human beta cells, the levels appeared to be dramatically reduced compared with those in the early developing pancreas (Fig. 8, ESM Fig. 9).

The production pattern of ARX in the developing mouse pancreas is less well characterised. $N g n 3^{-/-}$(also known as Neurog $3^{-/-}$) mice lack ARX-positive cells, suggesting that the production of ARX is initiated after production of NGN3 [2]. In adult mouse islets, ARX production is restricted to alpha cells. In the human pancreas, ARX production was detected at 9 weeks (Fig. 8, ESM Fig. 10). ARX production was observed in all cells producing both insulin and glucagon, while an additional population of ARX-producing cells was immunoreactive for neither of these hormones. By 13 to 14 weeks, ARX production was observed in all cells producing glucagon alone and in all cells co-producing glucagon and insulin (Fig. 8, ESM Fig. 10). In the adult islet, ARX production was restricted to the nucleus of alpha cells (Fig. 8, ESM Fig. 10). Thus it appears that during human fetal pancreas development, cells producing insulin alone or glucagon alone exhibit transcription factor profiles similar to those observed in the adult islet. Cells that co-produce both hormones appear to exhibit a transcription factor profile that mimics that of the mature alpha cell.

Characterisation of proliferation and apoptosis in cells coproducing insulin and glucagon The developing mouse pancreas exhibits a wave of proliferation and differentiation that occurs near E14 [29]. It is during this 'secondary transition' that the majority of fully differentiated endocrine cells appear. Subsequently, the endocrine cells begin to amass into organised structures that will become the mature islets. In the developing human pancreas, a similar wave of proliferation has not been described. Instead, it appears that the percentage of proliferating cells within the developing pancreatic epithelium begins high $(\sim 50 \%)$, then decreases to about $8 \%$ to $12 \%$ of the total cell population in the first 10 weeks post-conception, with less than $1 \%$ of insulinpositive cells exhibiting Ki67 immunoreactivity at this time [1]. Jeon and colleagues have suggested that insulinpositive cells exhibit little proliferative potential, while glucagon-positive cells are more proliferative during the period between 8 and 21 weeks of gestational age [30]. We observed widespread pancreatic epithelial proliferation at 9 weeks as indicated by proliferating cell nuclear antigen (PCNA) immunoreactivity (Fig. 9). The vast majority of insulin-positive cells observed at this age were not proliferating (Fig. 9). In contrast to the observations of Jeon and colleagues, we observed extensive proliferation of the pancreatic epithelium between 9 and 13 weeks, which then diminished dramatically by 15 weeks and remained low for the duration of development (Fig. 9). In agreement with a previous study [31], we found that the appearance of hormone production correlates with a loss of proliferative potential as assessed by PCNA immunoreactivity. This observation holds well for cells producing insulin and/or glucagon.

There is evidence to suggest that a transient wave of beta cell apoptosis occurs in the pancreas of neonatal rodents [32] and that this remodelling may play a role in generating mature islets. To our knowledge, such a wave of beta cell apoptosis has not been described in the developing human pancreas, nor is it known whether alpha cells or cells producing both insulin and glucagon undergo significant apoptosis during fetal development. To address this question, we characterised the production of cleaved caspase-3 in the developing pancreas (Fig. 9). Insulinproducing cells were rarely observed undergoing apoptosis. While we did find evidence of cleaved caspase- 3 production in cells producing glucagon with or without insulin, these cells were rare in number (Fig. 9). In addition, the percentage of cells co-producing insulin and glucagon, and also staining positive for cleaved caspase- 3 never exceeded 


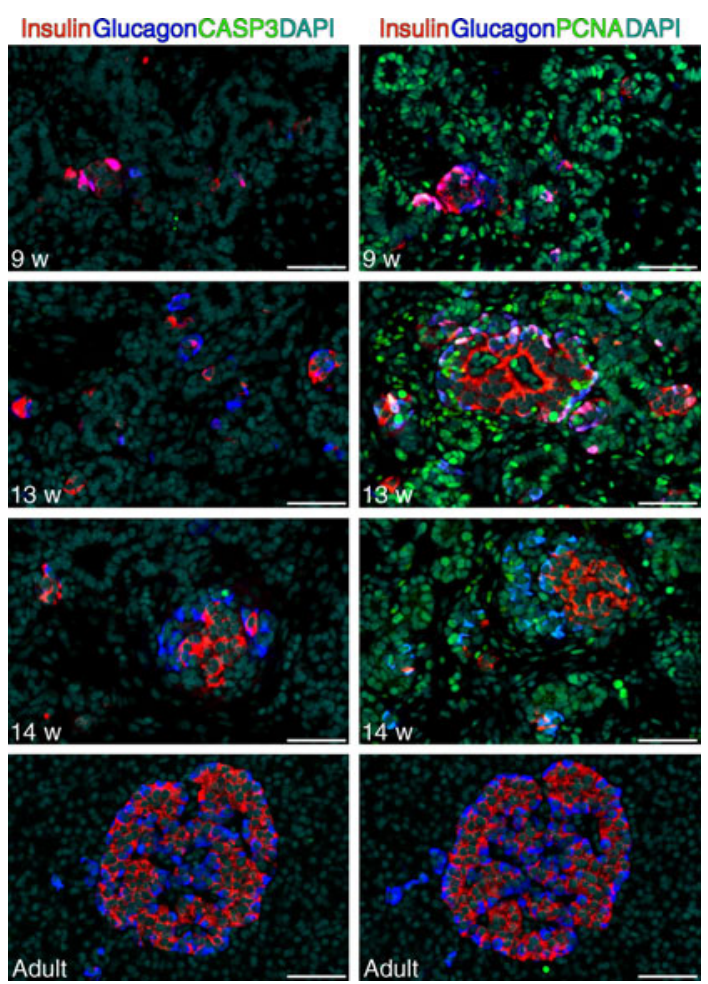

Fig. 9 Characterisation of apoptosis and proliferation among cells producing insulin and/or glucagon during human pancreas development. Triple immunofluorescence staining for insulin (red), glucagon (blue), and cleaved caspase-3 (green) or PCNA (green) in human fetal (age in weeks $[\mathrm{w}]$ as indicated) and adult pancreas sections. DAPI is shown in cyan. Scale bars, $50 \mu \mathrm{m}$

$0.85 \%$ of the total population of cells co-producing insulin and glucagon. Therefore, it is unlikely that these doublepositive cells undergo significant apoptosis at any point prior to 21 weeks.

\section{Discussion}

The hormone and transcription factor profiles of mature human alpha and beta cells differ significantly. While glucagon-producing alpha cells are characterised by the production of ARX and brain-specific homeobox 4 (BRN4) adult beta cells produce PDX1, NKX6.1 and MAFA. Many of these proteins exhibit a more promiscuous production pattern during fetal pancreas development. For example, we show here that PDX1 and NKX6.1 are produced throughout the developing pancreatic epithelium in early stages, but become restricted to their adult compartments between 13 and 15 weeks. In contrast, we found that production of ARX, PAX6 and NKX2.2 is highly restricted as early as 9 weeks. Hormone production is not restricted to individual separate cell populations during development, and the observation that endocrine cells within the developing pancreas produce several hormones has led to speculation that endocrine cells arise from a common precursor cell [33, 34]. The existence of cells that co-produce insulin and glucagon has been observed in humans and other mammalian species $[4,5,35]$. While the existence of such cells during human pancreas development has been well documented, their ultimate fate remains to be determined. Earlier lineage tracing studies in mice suggested that these double-positive cells were not capable of contributing to the adult endocrine cell population [6]; however, there has been no evidence to suggest that these cells undergo extensive apoptosis. In the current study, we performed an immunohistochemical analysis of transcription factor production in these cells that co-produce insulin and glucagon, in order to gain insights into their developmental path.

As the fetus develops, the pancreas undergoes a severalfold increase in overall size. A detailed morphometric analysis of whole human pancreas has been performed previously, showing a 15 -fold increase in organ weight between 8 and 16 weeks of gestation, and a 35-fold increase in weight by 21 weeks [23]. During this organ growth, the endocrine and exocrine compartments increase in size through a combination of proliferation and differentiation. Throughout fetal development and into adulthood, the relative size of the insulin- and glucagon-producing endocrine cell compartment remains stable, measuring between $1.5 \%$ and $3 \%$ of all pancreatic cells in our study. This suggests that the endocrine and exocrine compartment growth rates are similar. During this massive expansion of the endocrine compartment, the percentage of cells that produce insulin or glucagon, or both hormones varies. Between 9 and 16 weeks the insulin-only cell population decreases relative to the total endocrine cell pool, while glucagon-only cells increase in prevalence. Proliferation of existing alpha cells cannot account for the relative increase in the alpha cell population, as we observed little PNCA immunoreactivity in any hormone-producing cell populations. Interestingly, despite the $50 \%$ decrease in overall prevalence of cells co-producing insulin and glucagon between 9 and 21 weeks, we did not observe significant apoptosis in this cell population, suggesting that these cells 'transition' out of the dual hormone-producing state. On the basis of their transcription factor profile $\left(\mathrm{ARX}^{+} \mathrm{PDX}^{-}{ }^{-} \mathrm{NKX} 6.1^{-} \mathrm{NKX}^{2} .2^{+} \mathrm{PAX6}^{+} \mathrm{MAFA}^{-} \mathrm{MAFB}^{+}\right)$, we speculate that these dual-positive cells are precursors of mature alpha cells.

The findings of the present study may inform the processes of differentiating human pluripotent stem cells towards pancreatic endocrine cell types, including beta cells. We and others have observed extensive colocalisation of insulin and glucagon within differentiating cultures, and typically describe these cells as immature or fetal-like endocrine cells [36-38]. Lineage tracing of these polyhormonal intermediates has not been performed. 
Interestingly, however, cells that are derived from human embryonic stem cells and co-produce insulin and glucagon appear to mature into glucagon-only cells $[38,39]$. In contrast, a pancreatic endoderm enriched fraction of $\mathrm{PDX}^{+} / \mathrm{NKX} 6.1^{+}$cells gave rise to all pancreatic lineages, including functional insulinproducing cells [39]. These findings on differentiation of human embryonic stem cells support our speculation that the cells observed in fetal human pancreas that are copositive for insulin and glucagon may represent immature alpha cells.

Several recent studies have suggested that mature alpha cells in the rodent exhibit significant plasticity and can be transformed into insulin-producing beta cells following genetic or environmental manipulations [40-43]. In each of these studies, alpha cells passed through a transient state where they co-produced insulin and glucagon. Chung and colleagues observed induction of PDX1 and NKX6.1 production in alpha cells following pancreatic duct ligation and alloxan treatment, a development that resulted in the ectopic activation of insulin production [43]. Similarly, diphtheria toxin-mediated beta cell destruction resulted in insulin production in existing alpha cells [41]. Furthermore, glucagon promoter-driven PAX4 production resulted in alpha-to-beta cell transformation through a transient double-positive state [40]. The fact that alpha-to-beta cell conversion was capable of reversing diabetes in at least one model of hyperglycaemia [40] suggests that these newly formed beta cells can exhibit some functional insulin secretion. The apparent plasticity of endocrine cells in the adult rodent islet might duplicate aspects of the developing pancreas that transcend species. Coupling genetic lineage tracing with model transplant systems such as engrafting of human fetal pancreas under the kidney capsule $[31,44,45]$ or into the anterior chamber of the eye $[46,47]$ may help determine the ultimate fate of cells that co-produce insulin and glucagon during human pancreas development.

Acknowledgements Financial support for this project was provided by the Stem Cell Network (SCN; Ottawa, ON, Canada) and the Canadian Institutes of Health Research, Regenerative Medicine and Nanomedicine initiative. M.J. Riedel received support from the SCN. T.J. Kieffer is a Michael Smith Foundation for Health Research Senior Scholar.

Contribution statement All authors contributed to the conception and design, or analysis and interpretation of data, and drafting the article or revising it critically for important intellectual content. All authors gave final approval of the version to be published. In addition, RW provided human fetal pancreas sections and ZA and GLW provided human adult pancreas samples.

Duality of interest The authors declare that there is no duality of interest associated with this manuscript.

\section{References}

1. Piper K, Brickwood S, Turnpenny LW et al (2004) Beta cell differentiation during early human pancreas development. J Endocrinol 181:11-23

2. Collombat P, Mansouri A, Hecksher-Sorensen J et al (2003) Opposing actions of Arx and Pax4 in endocrine pancreas development. Genes Dev 17:2591-2603

3. Habener JF, Kemp DM, Thomas MK (2005) Minireview: transcriptional regulation in pancreatic development. Endocrinology 146:1025-1034

4. de Krijger RR, Aanstoot HJ, Kranenburg G, Reinhard M, Visser WJ, Bruining GJ (1992) The midgestational human fetal pancreas contains cells coexpressing islet hormones. Dev Biol 153:368375

5. Larsson LI, Hougaard DM (1994) Coexpression of islet hormones and messenger RNAs in the human foetal pancreas. Endocrine 2:759-765

6. Herrera PL (2000) Adult insulin- and glucagon-producing cells differentiate from two independent cell lineages. Development 127:2317-2322

7. Herrera PL, Huarte J, Zufferey R et al (1994) Ablation of islet endocrine cells by targeted expression of hormone-promoterdriven toxigenes. Proc Natl Acad Sci USA 91:12999-13003

8. Alpert S, Hanahan D, Teitelman G (1988) Hybrid insulin genes reveal a developmental lineage for pancreatic endocrine cells and imply a relationship with neurons. Cell 53:295-308

9. Fujita Y, Asadi A, Yang GK, Kwok YN, Kieffer TJ (2010) Differential processing of pro-glucose-dependent insulinotropic polypeptide in gut. Am J Physiol Gastrointest Liver Physiol 298: G608-G614

10. Malaisse-Lagae F, Stefan Y, Cox J, Perrelet A, Orci L (1979) Identification of a lobe in the adult human pancreas rich in pancreatic polypeptide. Diabetologia 17:361-365

11. Sander M, German MS (1997) The beta cell transcription factors and development of the pancreas. J Mol Med 75:327-340

12. St-Onge L, Sosa-Pineda B, Chowdhury K, Mansouri A, Gruss P (1997) Pax6 is required for differentiation of glucagon-producing alpha-cells in mouse pancreas. Nature 387:406-409

13. Heller RS, Stoffers DA, Liu A et al (2004) The role of Brn4/ Pou3f4 and Pax6 in forming the pancreatic glucagon cell identity. Dev Biol 268:123-134

14. Matsuoka TA, Artner I, Henderson E, Means A, Sander M, Stein R (2004) The MafA transcription factor appears to be responsible for tissue-specific expression of insulin. Proc Natl Acad Sci USA 101:2930-2933

15. Wang H, Brun T, Kataoka K, Sharma AJ, Wollheim CB (2007) MAFA controls genes implicated in insulin biosynthesis and secretion. Diabetologia 50:348-358

16. Zhang C, Moriguchi T, Kajihara M et al (2005) MafA is a key regulator of glucose-stimulated insulin secretion. Mol Cell Biol 25:4969-4976

17. Artner I, Blanchi B, Raum JC et al (2007) MafB is required for islet beta cell maturation. Proc Natl Acad Sci USA 104:3853-3858

18. Artner I, Le Lay J, Hang Y et al (2006) MafB: an activator of the glucagon gene expressed in developing islet alpha- and beta-cells. Diabetes 55:297-304

19. Sarkar SA, Kobberup S, Wong R et al (2008) Global gene expression profiling and histochemical analysis of the developing human fetal pancreas. Diabetologia 51:285-297

20. Kim H, Seed B (2010) The transcription factor MafB antagonizes antiviral responses by blocking recruitment of coactivators to the transcription factor IRF3. Nat Immunol 11:743-750

21. Sussel L, Kalamaras J, Hartigan-O'Connor DJ et al (1998) Mice lacking the homeodomain transcription factor $\mathrm{Nkx} 2.2$ have 
diabetes due to arrested differentiation of pancreatic beta cells. Development 125:2213-2221

22. Rudnick A, Ling TY, Odagiri H, Rutter WJ, German MS (1994) Pancreatic beta cells express a diverse set of homeobox genes. Proc Natl Acad Sci USA 91:12203-12207

23. Lyttle BM, Li J, Krishnamurthy M et al (2008) Transcription factor expression in the developing human fetal endocrine pancreas. Diabetologia 51:1169-1180

24. Pedersen JK, Nelson SB, Jorgensen MC et al (2005) Endodermal expression of Nkx6 genes depends differentially on Pdx1. Dev Biol 288:487-501

25. Sander M, Sussel L, Conners J et al (2000) Homeobox gene Nkx6.1 lies downstream of Nkx2.2 in the major pathway of betacell formation in the pancreas. Development 127:5533-5540

26. Johnson JD, Ahmed NT, Luciani DS et al (2003) Increased islet apoptosis in $\mathrm{Pdx}^{+/-}$mice. J Clin Invest 111:1147-1160

27. Holland AM, Hale MA, Kagami H, Hammer RE, MacDonald RJ (2002) Experimental control of pancreatic development and maintenance. Proc Natl Acad Sci USA 99:12236-12241

28. Collombat P, Hecksher-Sorensen J, Broccoli V et al (2005) The simultaneous loss of Arx and Pax 4 genes promotes a somatostatin-producing cell fate specification at the expense of the alpha- and beta-cell lineages in the mouse endocrine pancreas. Development 132:2969-2980

29. Pictet RL, Clark WR, Williams RH, Rutter WJ (1972) An ultrastructural analysis of the developing embryonic pancreas. Dev Biol 29:436-467

30. Jeon J, Correa-Medina M, Ricordi C, Edlund H, Diez JA (2009) Endocrine cell clustering during human pancreas development. J Histochem Cytochem 57:811-824

31. Castaing M, Duvillie B, Quemeneur E, Basmaciogullari A, Scharfmann R (2005) Ex vivo analysis of acinar and endocrine cell development in the human embryonic pancreas. Dev Dyn 234:339-345

32. Scaglia L, Cahill CJ, Finegood DT, Bonner-Weir S (1997) Apoptosis participates in the remodeling of the endocrine pancreas in the neonatal rat. Endocrinology 138:1736-1741

33. Lukinius A, Ericsson JL, Grimelius L, Korsgren O (1992) Ultrastructural studies of the ontogeny of fetal human and porcine endocrine pancreas, with special reference to colocalization of the four major islet hormones. Dev Biol 153:376-385

34. Bocian-Sobkowska J, Zabel M, Wozniak W, Surdyk-Zasada J (1999) Polyhormonal aspect of the endocrine cells of the human fetal pancreas. Histochem Cell Biol 112:147-153
35. Teitelman G, Alpert S, Polak JM, Martinez A, Hanahan D (1993) Precursor cells of mouse endocrine pancreas coexpress insulin, glucagon and the neuronal proteins tyrosine hydroxylase and neuropeptide Y, but not pancreatic polypeptide. Development 118:1031-1039

36. D'Amour KA, Bang AG, Eliazer S et al (2006) Production of pancreatic hormone-expressing endocrine cells from human embryonic stem cells. Nat Biotechnol 24:1392-1401

37. Jiang J, Au M, Lu K et al (2007) Generation of insulin-producing islet-like clusters from human embryonic stem cells. Stem Cells 25:1940-1953

38. Rezania A, Riedel MJ, Wideman RD et al (2011) Production of functional glucagon-secreting alpha-cells from human embryonic stem cells. Diabetes 60:239-247

39. Kelly OG, Chan MY, Martinson LA et al (2011) Cell-surface markers for the isolation of pancreatic cell types derived from human embryonic stem cells. Nat Biotechnol 29:750-756

40. Collombat P, Xu X, Ravassard P et al (2009) The ectopic expression of $\mathrm{Pax} 4$ in the mouse pancreas converts progenitor cells into alpha and subsequently beta cells. Cell 138:449462

41. Thorel F, Nepote V, Avril I et al (2010) Conversion of adult pancreatic alpha-cells to beta-cells after extreme beta-cell loss. Nature 464:1149-1154

42. Lu J, Herrera PL, Carreira C et al (2010) Alpha-cell-specific Men1 ablation triggers the transdifferentiation of glucagon-expressing cells and insulinoma development. Gastroenterology 138:19541965

43. Chung CH, Hao E, Piran R, Keinan E, Levine F (2010) Pancreatic beta-cell neogenesis by direct conversion from mature alpha-cells. Stem Cells 28:1630-1638

44. Castaing M, Peault B, Basmaciogullari A, Casal I, Czernichow P, Scharfmann R (2001) Blood glucose normalization upon transplantation of human embryonic pancreas into beta-cell-deficient SCID mice. Diabetologia 44:2066-2076

45. Scharfmann R, Xiao X, Heimberg H, Mallet J, Ravassard P (2008) Beta cells within single human islets originate from multiple progenitors. PLoS One 3:e3559

46. Speier S, Nyqvist D, Kohler M, Caicedo A, Leibiger IB, Berggren PO (2008) Noninvasive high-resolution in vivo imaging of cell biology in the anterior chamber of the mouse eye. Nat Protoc 3:1278-1286

47. Speier S, Nyqvist D, Cabrera O et al (2008) Noninvasive in vivo imaging of pancreatic islet cell biology. Nat Med 14:574-578 